\title{
CRIMSONpublishers
}

http://www.crimsonpublishers.com

\section{Acute Pyelonephritis of Crossed Right Fused Renal Ectopia}

\author{
Tudevdorj Sanjsambuu ${ }^{1}$, Javkhlantur Bayarlakh ${ }^{1}$, Bat-Ireedui Badarch ${ }^{1}$, Ganbat Ochir ${ }^{1}$ and Batsaikhan Bat- \\ Erdene $^{2 *}$ \\ ${ }^{1}$ Department of Surgery, The First Central Hospital of Mongolia \\ ${ }^{2}$ Department of Surgery, Mongolian National University of Medical Science
}

*Corresponding author: Batsaikhan Bat-Erdene, Department of Surgery, Mongolian National University of Medical Science. S.Zorig Street, Ulaanbaatar, Mongolia, Italy

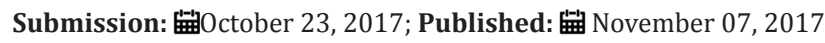

\begin{abstract}
Crossed Fused Renal Ectopia (CFRE) is a rare uncommon anatomic anomaly, which often goes undiagnosed. Here we report a case of acute pyelonephritis of crossed right fused renal ectopia, which was diagnosed after operation appendectomy by contrast computed tomography (CT) in developing country like Mongolia. Crossed fused renal ectopia was detected in most patients by different causes, the reason of challenges were deficit of instruments or knowledge of medical doctor in low-income country.
\end{abstract}

Keywords: Crossed fused renal ectopia; Pyelonephritis; Computed tomography

\section{Introduction}

A 39 years old women transported by ambulance doctor, the patient hospitalized with complaints of left lower abdominal pain, elevated temperature $38{ }^{\circ} \mathrm{C}-39{ }^{\circ} \mathrm{C}$, vomiting 3-4 times, which were started 2 days ago. The patient's condition during admission was blood pressure 135/95mmHg, pulse 94 and saturation $98 \%$. We had taken blood for CBC, biochemistry, immunology test and coagulagrama. We had done ultrasonography, which was suggestive of the acute appendicitis. There were not mentioned about acute puelonephritis of crossed fused renal ectopia. A contrast-enhanced computed tomography (CT) is not charged by health insurance, the patient could not pay by themselves. Alvarado score was 7-8 points.

The complete blood count showed elevated WBC-

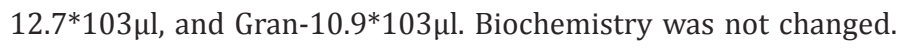
Coagulagramme was not changed.

The patient was done open appendectomy with spinal anesthesia. The histological result showed the acute phlegmonous appendicitis, however the some symptoms like fever, vomiting, and pain in right lower abdominal were continued postoperative day 1.

We suggested the patient to do a contrast-enhanced computed tomography (CT), which showed the crossed fused renal ectopia (Figure $1 \& 2$ ).
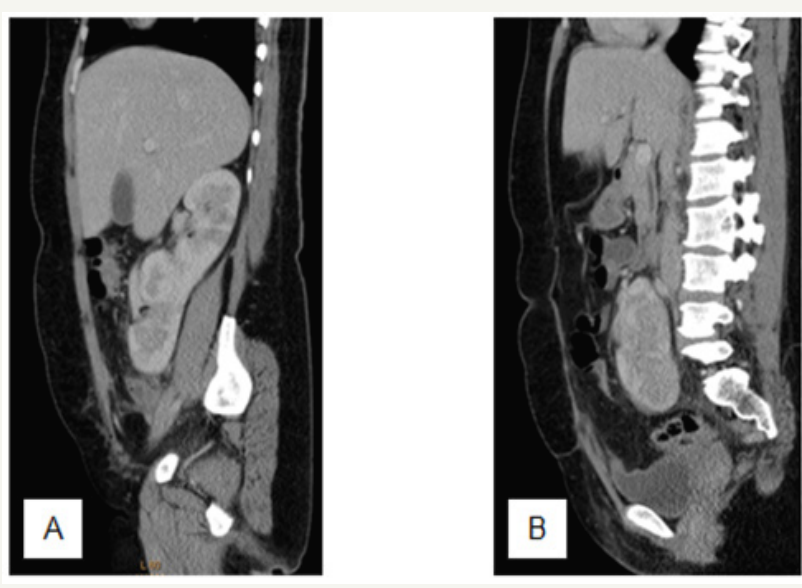

Figure 1: Sagittal view of crossed fused right renal ectopia.

\section{Discussion}

CFRE is the second common fusion anomaly after horseshoe kidney [1], which is asymptomatic and go undiagnosed until making an imaging by some reasons, which were in our case the appendix inflamed secondly. The urinary tract system anomalies possess $3 \%$ in all congenital anomalies [2]. 

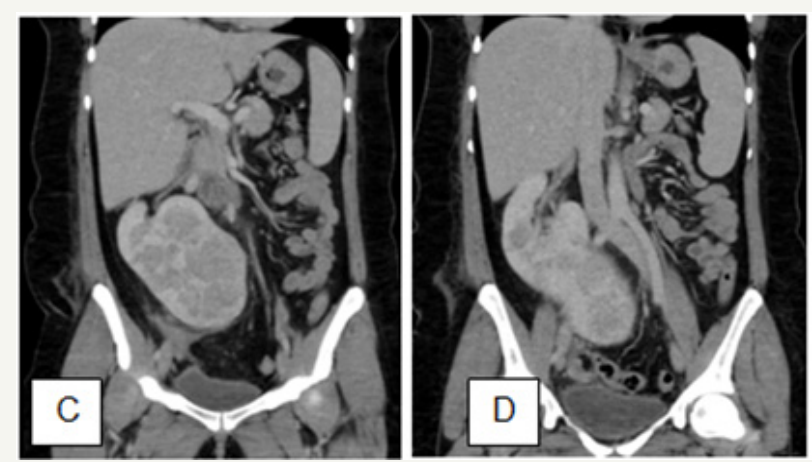

Figure 2: Coronal view of crossed fused right renal ectopia.

CFRE is classified into 4 main categories: crossed renal ectopia with or without fusion, unilateral crossed renal ectopia and bilateral crossed renal ectopia without fusion [3]. 85\%-90\% of the crossed renal ectopia cases are partially or completely fused. CFRE happens two times more in men than women [4].

The ultrasonography identify the crossed fused renal ectopia, which includes an anterior and posterior both with difference in orientation of the 2 collecting systems in the fused kidneys [5].

Shailesh.S reported detection of crossed fused renal ectopia was in most patients for different investigation of disease [6]. In here we try to describe the challenges of diagnosis of CFRE, which was secondly detected after appendectomy operation. Computed tomography with contrast identifies definitely the anomaly, however that CT is not available for everybody in low-income country as a Mongolia.

\section{Conclusion}

The important issue is to detect the CFRE is an experienced radiologist, who could diagnose by ultrasound in the first examination, which is available in hospital of developing country.

\section{References}

1. Shapiro E, Bauer SB, Chow JS (2012) Anomalies of upper urinary tract. In: Wein AJ, Kavoussi LR, et al. (Eds.), Campbell-Walsh Urology. Philadelphia: Elsevier Saunders, USA, pp. 3140-3145.

2. Khan B, Khade B, Patil G (2013) Unilateral ectopic kidney with associated anomalies: a case report. International Journal of Recent Trends in Science and Technology 9(1): 29-32.

3. McDonald JH, McClellan DS (1957) Crossed renal ectopia. Am J Surg 93(6): 995-999.

4. Sharma V, Babu CSR, Gupta OP (2014) Crossed fused renal ectopia multidetector computed tomography study. Int J Anat Res 2(2): 305-309.

5. Goodman JD, Norton KI, Carr L, Hsu-Chong Y (1986) Crossed fused renal ectopia: Sonographic diagnosis. Urol Radiol 8: 13-16.

6. Solanki S, Bhatnagar V, Gupta AK, Kumar R (2013) Crossed fused renal ectopia: Challenges in diagnosis and management. Journal of Indian Association of Pediatric Surgeons 18(1): 7-10. 